J. R. Kastner • M. A. Eiteman · S. A. Lee

\title{
Effect of redox potential on stationary-phase xylitol fermentations using Candida tropicalis
}

Published online: 27 February 2004

(C) Springer-Verlag 2004

\section{Appl Microbiol Biotechnol (2003) 63:96-100}

Throughout the paper the redox values in the text should be negative (e.g., $-100 \mathrm{mV}$ and not $100 \mathrm{mV}$ ), except for the zero value $(0 \mathrm{mV})$ and the value reported and referenced to Oh et al., 1999 (p.99). Most of the reported redox values in the text read positive when they should be negative (the values in the tables and figures are correct). 